\title{
Efectos de la intervención logoterapéutica con padres de hijos desaparecidos. El caso de San Miguel Totolapan (México)*
}

Effects of the logotherapeutic intervention on parents with missing children. The case of San Miguel Totolapan (Mexico)

Efeitos da intervenção logo terapêutica com pais de filhos desaparecidos. O caso de San Miguel Totolapan (México)

Recibido el 11 septiembre de 2015. Aceptado el 4 de febrero de 2016.

Para citar este artículo:

Arreola Piñon, Cinthia Gricell;

Contreras Piedra, María

Guadalupe y Gómez del

Campo del Paso, María Inés

(junio, 2016). Efectos de la

intervención logoterapéutica

con padres de hijos

desaparecidos. El caso de San

Miguel Totolapan (México).

Ánfora, 23(40), 99-120.

Universidad Autónoma de

Manizales. ISSN 0121-6538.
Cinthia Gricell Arreola Piñón**

México

María Guadalupe Contreras Piedra***

México

María Inés Gómez del Campo del Paso****

México

\section{Resumen}

Objetivo: evidenciar los efectos de un taller vivencial logoterapéutico orientado a la resignificación del sentido de vida y el sufrimiento de un grupo de padres que tienen hijos desaparecidos. Metodología: la

\footnotetext{
* Este trabajo se realizó como una investigación con fines de titulación "Intervención logo-terapéutica con padres de hijos desaparecidos. el caso de San Miguel Totolapan" de la licenciatura en Psicología por parte de la Universidad Michoacana de San Nicolás de Hidalgo, Se realizó entre los meses de febrero a julio de 2015. No contó con ningún tipo de financiamiento.

** Pasante de la facultad de psicología de la Universidad Michoacana de San Nicolás de Hidalgo, Morelia, Michoacán México. Correo electrónico: citlali.29@hotmail.com

*** Pasante de la facultad de psicología de la Universidad Michoacana de San Nicolás de Hidalgo. Morelia, Michoacán, México. Correo electrónico: ma.piedra@hotmail.com

Doctora en psicología, profesora investigadora de la Universidad Michoacana de San Nicolás de Hidalgo, Michoacán, México. Correo electrónico: igomezdelcampo@hotmail.com
} 
metodología empleada es cualitativa; el estudio se realizó en San Miguel Totolapan, municipio del Estado de Guerrero (México) con la participación de 4 padres de familia (3 mujeres y un hombre). La estrategia de intervención fue un taller vivencial desde un enfoque logoterapéutico de 5 sesiones. Resultados: se encontró que los participantes pudieron expresar con seguridad sus sentimientos, valoraron las cosas agradables de su vida, a pesar de su pérdida y manifestaron el deseo de convivir con la gente y sobre todo resignificaron el valor de la familia en sus vidas. Conclusiones: se considera que realizar intervenciones poniendo énfasis en encontrar un nuevo sentido de vida, para evitar paralizarse en el sufrimiento, resulta beneficioso en los casos de personas desaparecidas, ya que permite sobrellevar la pérdida.

Palabras claves: Logoterapia, Duelo, Sentido de vida, Sentido de sufrimiento.

\section{Abstract}

Objective: to demonstrate the effects of a Logotherapeutic experiential workshop, which aimed at redefining the meaning of life and suffering of a group of parents with missing children. Methodology: this qualitative study was conducted in San Miguel Totolapan, municipality of the State of Guerrero (Mexico), with the participation of 4 parents ( 3 women and 1 man). The intervention strategy was carried out from the logotherapeutic approach, through five sessions of an experiential workshop. Results: it was found that the participants could express their feelings with conviction. Despite their loss, they showed appreciation for the pleasant things of their lives, they expressed the desire to live and, mainly, resignified the value of family. Conclusions: it was concluded that the interventions, that allow individuals to find a new meaning of life and overcome suffering, are beneficial in cases of missing people, since these ones help them to endure the loss.

Keywords: Logotherapy, Mourning, Meaning of life, Sense of Suffering.

\section{Resumo}

Objetivo: evidenciar os efeitos de um atelier vivencial logo terapêutico orientado à ressignificação do sentido de vida e o sofrimento de um grupo de pais com filhos desaparecidos. Metodologia: estudo qualitativo; realizou-se em San Miguel Totolapan, município do Estado de Guerrero (México) com a participação de quatro pais de família (três mulheres e um homem). A estratégia de intervenção foi um atelier vivencial desde um enfoque logo terapêutico de cinco sessões. Resultados: encontrou-se que os participantes puderam expressar com seguridade seus sentimentos, valorizaram 
Arreola Piñon, Cinthia Gricell; Contreras Piedra, María Guadalupe y Gómez del Campo del Paso, María Inés (junio, 2016). Efectos de la intervención logoterapéutica con padres de hijos desaparecidos. El caso de San Miguel Totolapan (México). Ánfora, 23(40), 99-120. Universidad Autónoma de Manizales. ISSN 0121-6538.

as coisas agradáveis de sua vida, apesar de sua perda e manifestaram o desejo de conviver com as pessoas; e especialmente, ressignificaram o valor da família em suas vidas. Conclusões: concluiu-se que as intervenções que encontrem um novo sentido de vida, para evitar paralisar-se no sofrimento, resultam benéficas nos casos de pessoas desaparecidas, já que permitem sobrelevar a perda. 


\section{Palavras chave: Logo terapia, Luto, Sentido de vida, Sentido de sofrimento.}

\section{Introducción}

En diversas problemáticas de seguridad social, como son sobornos, secuestros, homicidios y personas desaparecidas, está sumergida la población de San Miguel de Totolapan ${ }^{5}$. Según Amnistía Internacional (citado por Benenson, 2015), este hecho se ha incrementado, pues las cifras publicadas en octubre de 2014, muestran que 22.610 personas han desaparecido desde el 01 de diciembre del 2006 y en octubre del 2014 aún se desconoce su paradero.

De acuerdo con estadísticas del Registro Nacional de Datos de Personas Extraviadas o Desaparecidas (RNPED) casi el $50 \%$ de esas desapariciones tuvieron lugar entre 2012 y 2014. El 50\% de los desaparecidos son originarios de los Estados de Tamaulipas con 4,875 casos; Jalisco con 2,113; Estado de México con 1,554; Distrito Federal con 1,450 y Coahuila con 1,332; en el Estado de Guerrero suman más de 646 desaparecidos de acuerdo con la Procuraduría General de la República (2015). Sierra (2015) encuentra que las desapariciones forzadas son una prueba cotidiana del derrumbe de las instituciones y del impacto del crimen organizado en ellas y sobre la población.

Los pobladores de San Miguel Totolapan refieren que ha habido un aumento de delincuencia desde hace 9 años aproximadamente, entre los hechos que se relatan están: secuestros, homicidios, ajustes de cuentas y desapariciones forzadas. Existen rumores constantes de la participación de autoridades municipales y estatales en estos hechos, aunque no hay forma de confirmarlo. Por lo que la población vive con miedo, una incertidumbre por su futuro y el de sus familias y con profunda desconfianza en las autoridades.

A partir de testimonios de los pobladores y de publicaciones en la página de Facebook ${ }^{6}$ se ha observado que a los padres les parece peligroso buscar información sobre el paradero de sus hijos; o solicitar ayuda a las autoridades o asociaciones civiles, por lo que las únicas manifestaciones públicas que se presentan al respecto ante las desapariciones son la realización de novenas,

\footnotetext{
5. Población ubicada en la región de tierra caliente del Estado de Guerrero. Su nombre deriva del náhuatl formado con los términos "totol/totole" y "apan" que significa Rio donde se crían los guajolotes". San Miguel cuenta con 28,009 habitantes según las estadísticas del Instituto Nacional de Estadística y Geografía (INEGI, 2011). 
rosarios y misas celebradas en honor al santo patrón el Arcángel San Miguel, para que ayude a los desaparecidos a regresar. Se puede suponer que a partir de esa desconfianza, se dificultó la participación de las personas en el taller que desarrolló el presente estudio.

Por otra parte, en San Miguel Totolapan no existe ningún servicio de apoyo psicológico. Ya que las dependencias de salud (Centro de Salud) y de bienestar familiar (oficina de Desarrollo Integral de la Familia DIF) no cuenta con un psicólogo entre su personal; tampoco se dispone de un psicólogo particular.

La asociación civil que más se ha encargado de las desapariciones forzadas es Amnistía Internacional (citado por Benenson, 2015) quien define a las personas desaparecidas como aquéllas de las cuales sus familiares no tienen noticias, después de 72 horas. Los tipos de desapariciones son:

Desapariciones Comunes: un día salen de su casa y no regresan, se desconocen los móviles del hecho, no tienen antecedentes políticos, ni judiciales, simplemente no regresan más. No hay llamadas, ni amenazas.

Desaparición forzada: se presenta en aquellas personas que han sido detenidas por agentes del Estado, pero cuyo paradero y suerte se ocultan y cuya detención se desmiente.

Desaparición eterna: se presenta cuando el desaparecido puede ser asesinado y los familiares nunca lo encuentran ni vivo, ni muerto.

La mayoría de las víctimas son jóvenes y hombres de entre 17 y 50 años. Muchas víctimas recorrían un trayecto habitual cuando fueron obligadas a detenerse por hombres armados o por fuerza de seguridad en controles. Algunas acababan de salir de casa para ir a una tienda cercana o para visitar a un amigo, pero nunca regresaron; se desconoce la suerte que han corrido las víctimas, pero muchas familias sospechan que varias fueron reclutadas por la fuerza para trabajar en organizaciones delictivas, que en ocasiones operan en conveniencia de la policía o con las fuerzas de seguridad (Benenson, 2015).

Es trágico darse cuenta de que alguien a quien se quiere no está ni aquí ni allí. Pero al mismo tiempo y a pesar de tan fuerte estrés, la pérdida puede producir algún beneficio como nuevas maneras de ser que encierran alguna finalidad y una probabilidad de crecimiento. De ahí la importancia de la resignificación del sentido de vida y del sentido de sufrimiento. 
Al respecto, la psicología presenta distintas estrategias de intervención: Villalobos (2015) propone un taller de estrategias para aprender a manejar las pérdidas en la cual da a conocer una serie de recomendaciones para quienes acompañan a una persona que ha tenido una pérdida:

> No hace falta hablar, puede ser más recomendable tener disposición a escuchar; las frases hechas puede que no sirvan de nada. -A una persona que está pasando por un proceso de duelo no hace falta animarlas o tranquilizarlas, lo recomendable es tener la disposición de escuchar y para ello es necesario dejar que quien está en duelo se desahogue; esto implica, respetar su llanto, dejar que hable e incluso tener paciencia si se enoja y expresa su ira o su tristeza. -El contacto es importante, no basta una sola visita, una llamada por teléfono, un correo electrónico. -En casos muy drásticos es posible que el duelo no se pueda superar por los propios recursos, ni aun con el apoyo de la familia; en esos casos es recomendable buscar ayuda profesional.

Soria (2014) propone una forma de intervención con padres de hijos desaparecidos a través de la escritura de cartas de los padres a sus hijos desaparecidos. La carta tiene como función dar testimonios escritos hacia los desaparecidos que desde la ausencia de respuesta de los otros (las autoridades) se configura, así como el encuentro de las palabras plasmadas y las dirigidas a otro, pero expuestas públicamente.

En el proceso de duelo, según Giralda, Gómez y Maestre (2008) las personas experimentan manifestaciones emocionales, cognitivas y conductuales que anticipan un proceso cuyo fin es adaptarse a la ausencia de aquello que se perdió. Sin embargo, en el caso de las desapariciones el duelo se prolonga por la esperanza de que el desaparecido regrese, dificultando la conclusión del duelo, aun después de años de acontecido el evento traumático.

De esta manera, el duelo por la desaparición de personas es una situación que requiere mayor estudio y estrategias de intervención de la psicología, ya que es necesario no sólo escuchar las voces y reclamos de los familiares que han perdido a sus seres amados, sino también realizar intervenciones que les ayuden a sobrellevar esta situación encontrándole un sentido más amplio.

Bravo, Duran y Trujano (2014) definen distintos tipos de duelo: duelo complicado, es decir, un modo de nombrar la pérdida que siempre tendrá que ver con la pérdida del amor, de anhelos, de deseos; el duelo crónico es aquel que tiene 
una duración excesiva y nunca llega a una conclusión satisfactoria. Este tipo de duelo es bastante fácil de diagnosticar, porque la persona que lo sufre es muy consciente de que no consigue acabarlo. También puede presentarse un duelo prolongado, ya que las personas que experimentan esta dificultad son plenamente conscientes de que no están llegando a una resolución adecuada del duelo, pues la pérdida se ha producido hace ya muchos meses o a veces años.

Y está el duelo patológico, en el que las personas sufren una pérdida repentina o que se produce en condiciones horribles; los que están aislados socialmente, los que se sienten responsables (reales o imaginarios) de la pérdida, los que arrastran historias de pérdidas traumáticas y los que tienen una intensa relación de ambivalencia o dependencia con la persona fallecida. En el caso de desapariciones es común que se dé cualquiera de estos tipos de duelo, por la incertidumbre de la pérdida que no permite la conclusión del proceso.

En los casos duelo, en los que existe la certeza de la muerte Corless, Germino y Pittmann (2005) definen tres componentes interrelacionados en el proceso de duelo que lo conforman: pérdida, aflicción y resolución.

La pérdida se refiere a la separación de una parte de la propia vida con la cual se tiene un vínculo emocional; la aflicción alude a las complejas reacciones emocionales, cognitivas y perceptuales que acompañan a la pérdida, es factible conocer una variedad de trayectorias y expresiones cuyo carácter puede moldearse en función de la naturaleza e intensidad de las pérdidas que se experimentan. La resolución es el componente final en sobrevivir la muerte de un ser amado. Tal término se emplea aquí para referir no al punto final de la aflicción, si no el proceso mediante el cual los individuos manejan las circunstancias de sus vidas a medida que pasa el tiempo (Corless, Germino y Pittmann, 2005).

Aunque en dicho proceso intervienen los factores externos y los recursos con los que la persona cuenta para enfrentar la pérdida, fundamentalmente tiene que ver con el sentido que las personas le dan a su vida, es decir, la motivación última que lleva a la persona a asumir ciertas actitudes y valores para encaminar su vida a un fin determinado (Frankl, 1994).

A propósito, la logoterapia es un método psicoterapéutico creado por el Dr. Viktor Emil Frankl orientado a descubrir el sentido de la vida, por medio de una educación destinada a fomentar la responsabilidad del individuo (Fabry, 2005). Así mismo, se presenta como un auxilio para que la gente diga sí a la vida, no importa si el sufrimiento es causado por relaciones humanas difíciles, conflictos 
en su empleo, la muerte de un ser querido o deriva de problemas ocasionados por sí mismo.

En este caso, por ejemplo los padres que tienen hijos desaparecidos, que su sufrimiento fue generado por agentes externos y como resultado de ese sufrimiento el sentido de vida se ha perdido, la logoterapia tiene como supuesto que en lo profundo de la dimensión espiritual, la persona sabe qué clase de personas es, cuáles son sus potenciales y qué es lo más importante y significativo para sí.

Por tal motivo, se considera que la logoterapia permite la perspectiva del hombre como un ser cuya vida está integrada por una serie de situaciones que poseen un sentido específico que solo le pertenece a él; encontrar el sentido a cada situación de la vida, con los recursos que posee la persona influye en su felicidad e incluso en su salud mental (Fabry, 2005). La logoterapia describe conceptos como el sentido del sufrimiento y el sentido de vida, los cuales se presentan en esta investigación como conceptos centrales.

Respecto al sentido de sufrimiento, Frankl (1991) explica que aún en el dolor y el sufrimiento, cuando difícilmente se vislumbra una meta, la elección de actitud permanece abierta y es esta actitud de asumir el sufrimiento como una forma de crecimiento y trascendencia lo que permite alejar el dolor y encontrarle dignidad y sentido a la experiencia, por difícil que sea.

La logoterapia parte del convencimiento de que el sentido de la vida no se pierde bajo ninguna circunstancia. Sin embargo, no es estático, sino que debe percibirse en las distintas situaciones de una forma nueva, modificada o adaptada que permita a la persona resignificar su vida (Lukas, 2003)

Afirma Lukas (2003) que "No hay ninguna situación en la vida que carezca realmente de sentido, esto se deduce al hecho de que los lados aparentemente negativos de la existencia humana, especialmente la triada trágica formada por el sufrimiento, la culpa y la muerte también pueden adoptar la forma de algo positivo, de una exigencia si se tratan con la actitud y la postura correcta" (p. 23). Por su parte, Frankl (1994) considera que la clave para adoptar una visión positiva de la vida, es el convencimiento de que ésta tiene sentido en cualquier circunstancia y que todos tenemos la capacidad de encontrarlo, logrando sobreponerse a las enfermedades y golpes del destino, si le encuentra sentido a su existencia. 
Por lo anterior que surge la necesidad de la creación de un taller que brinde la posibilidad de que los padres logren la búsqueda de sus potencialidades para la resignificación del sufrimiento que están viviendo y de esta manera darle un valor y buscar el sentido de vida y mejorar la su calidad. Como la voluntad del sentido es la más poderosa motivación para vivir y actuar, los humanos son seres en busca de sentido. Visualizar el sentido de su vida les permite desarrollar sus capacidades y soportar contratiempos. El sentido no es ni un subproducto ni un medio para lograr un fin: es la meta última (Fabry, 2001)

Para Lukas (2008) no hay ningún ser humano que no siga teniendo una posibilidad de superarse a sí mismo, ninguna situación de la vida en la que no se pueda descubrir y atizar alguna chispa de sentido.

Al respecto, Frankl (1991), expone que:

El sentido del sufrimiento se presenta para encontrar un sentido de vida. Cuando uno se enfrenta con un destino ineludible, inapelable e irrevocable entonces la vida ofrece la oportunidad de realizar el valor supremo, de cumplir el sentido más profundo: aceptar el sufrimiento. El valor no reside en el sufrimiento en sí, sino en la actitud frente al sufrimiento, en nuestra actitud para soportar ese sufrimiento. El sufrimiento no es necesario para otorgarle sentido a la vida. Este es posible sin el sufrimiento o a pesar del sufrimiento. Para que este confiera un sentido, ha de ser un sufrimiento inevitable, absolutamente necesario (p. 113).

Por lo anterior, surgen las siguientes inquietudes: ¿es posible para los padres encontrar un sentido de vida que trascienda la desaparición de uno de sus hijos?, ¿se puede llegar a la resolución del duelo por la desaparición de un hijo?, ¿cuáles son los recursos que los padres pueden utilizar para resolver ese duelo?, ¿la participación en un taller logoterapéutico propicia la utilización de estos recursos para la resolución del duelo?, o ¿para la resignificación de su vida?

La presente investigación plantea la utilización de los talleres logoterapéuticos como estrategia para favorecer la resolución del duelo por la desaparición de un hijo, lo que lleva al planteamiento del siguiente objetivo general: evidenciar los efectos de un taller vivencial logoterapéutico orientado a la resignificación del sentido de vida y el sufrimiento de un grupo de padres que tienen hijos desaparecidos y los objetivos específicos: identificar los recursos personales de los padres, describir las estrategias que utilizan para sobrellevar el duelo e identificar si el taller propicia el surgimiento de otro sentido de vida en los padres. 
Dado que en la actualidad se han venido suscitando varios casos sobre desapariciones forzadas, es importante y de gran relevancia social brindar una atención integral a aquellas víctimas, dado que la comprensión de un sentido se ha perdido, afectando así grandes aspectos de la vida de la víctima, por ejemplo, en el área laboral, relaciones interpersonales, familiar y conyugal, afectando la estabilidad personal de la víctimas. Se pretende que la psicología ayude al fortalecimiento del potencial que se ha visto truncado cuando presenta una dificultad para concluir el duelo, así como la pérdida del sentido de vida.

\section{Metodología}

Esta investigación se realizó a través de una metodología cualitativa de tipo fenomenológico, la cual no busca la representatividad o generalización de los resultados sino la profundización en un fenómeno particular (Rodríguez y colaboradores, 1999).

Participantes: 4 padres y madres de familia que viven en San Miguel Totolapan, Estado de Guerrero, México. Ya que en esta población se han presentado varios casos de desaparición de personas, no se encontraron cifras oficiales, pero se sabe por testimonios de al menos 15 personas desaparecidas

El taller se llevó a cabo con la participación de tres madres de familia y un padre. Las edades están entre los 40 a 60 años, tienen entre dos y cuatro hijos, de bajos recursos económicos, todos vecinos de la comunidad; se dedican a actividades diversas como agricultura, venta de comida, fabricación y venta de artesanías y cuidado del hogar; las cuatro familias se consideran devotas de la iglesia católica.

Los hijos desaparecidos son hombres de edades de 19 a 35 años, desaparecidos entre 2010 y 2014; en la actualidad se encuentran en paradero desconocido.

Procedimiento: se realizó la planeación e implementación de un taller vivencial con un enfoque logoterapéutico que consta de 5 sesiones de dos horas de duración cada una. A continuación se presentan en la tabla 1 las actividades realizadas. 
Tabla 1. Técnicas utilizadas en el taller.

\begin{tabular}{|c|c|c|c|}
\hline $\begin{array}{l}\text { Número se } \\
\text { sesiones }\end{array}$ & $\begin{array}{l}\text { Objetivo } \\
\text { específico }\end{array}$ & Sustento teórico & Estrategia \\
\hline $\begin{array}{c}\text { Sesión No.1 } \\
\text { Rompe el hielo }\end{array}$ & $\begin{array}{l}\text { Que los participan- } \\
\text { tes y facilitadores } \\
\text { se conozcan, esta- } \\
\text { bleciendo empatía } \\
\text { y generando un } \\
\text { clima de confianza. }\end{array}$ & $\begin{array}{l}\text { La creación de un ambiente } \\
\text { de empatía según Luna } \\
\text { (2002) favorece el desarro- } \\
\text { llo de confianza entre los } \\
\text { participantes y de esta ma- } \\
\text { nera la genera la apertura } \\
\text { del sentimiento. Cuando la } \\
\text { persona se siente escucha- } \\
\text { da, aceptada así como es, } \\
\text { posibilita en insight, una } \\
\text { comprensión súbita de su } \\
\text { situación. }\end{array}$ & $\begin{array}{l}\text { Se inició presentando el taller } \\
\text { y, posteriormente la presenta- } \\
\text { ción de las facilitadores para } \\
\text { proseguir con los participantes, } \\
\text { contestando las siguientes pre- } \\
\text { guntas ¿Qué te gusta hacer en } \\
\text { tus ratos libres? ¿Cuáles crees } \\
\text { que son tus habilidades como } \\
\text { persona para afrontar la vida } \\
\text { y menciona un recuerdo en el } \\
\text { cual hayas puesto en práctica } \\
\text { esos recursos que mencionas? }\end{array}$ \\
\hline $\begin{array}{l}\text { Sesión No.2 } \\
\text { Fotobiografía }\end{array}$ & $\begin{array}{l}\text { Que los partici- } \\
\text { pantes comiencen } \\
\text { a dar sentido a su } \\
\text { vida a partir de } \\
\text { lo que vivieron en } \\
\text { compañía de sus } \\
\text { hijos. }\end{array}$ & $\begin{array}{l}\text { Esta estrategia está } \\
\text { formulada con base en el } \\
\text { método logoterapéutico de } \\
\text { la intención paradójica la } \\
\text { cual Lukas (2003) describe } \\
\text { como un distanciamiento } \\
\text { de los factores desencade- } \\
\text { nantes }\end{array}$ & $\begin{array}{l}\text { Se solicitó a los padres la } \\
\text { formación de la biografía de sus } \\
\text { hijos con fotografías que ellos } \\
\text { eligieron para posteriormente } \\
\text { compartir la biografía de sus } \\
\text { hijos, con esto se complementa } \\
\text { el conectar, abrir los senti- } \\
\text { mientos, crear un ambiente } \\
\text { de empatía y comenzar a dar } \\
\text { sentido a su vida a partir de lo } \\
\text { que vivieron en compañía de } \\
\text { sus hijos. Recordando que para } \\
\text { Corless, Germino, Pittmann } \\
\text { (2005) el recordar los mo- } \\
\text { mentos agradables se consi- } \\
\text { dera parte de la resolución del } \\
\text { duelo. }\end{array}$ \\
\hline
\end{tabular}




\begin{tabular}{|c|c|c|c|}
\hline $\begin{array}{l}\text { Número se } \\
\text { sesiones }\end{array}$ & $\begin{array}{l}\text { Objetivo } \\
\text { específico }\end{array}$ & Sustento teórico & Estrategia \\
\hline $\begin{array}{c}\text { Sesión No.3 } \\
\text { Diálogo } \\
\text { socrático }\end{array}$ & $\begin{array}{c}\text { Guiar a los parti- } \\
\text { cipantes hacia el } \\
\text { autodescubrimien- } \\
\text { to, las alternativas } \\
\text { de elección, la } \\
\text { responsabilidad } \\
\text { y la autotrascen- } \\
\text { dencia. }\end{array}$ & $\begin{array}{l}\text { Esta estrategia tiene su } \\
\text { base en la modulación de } \\
\text { la actitud cuyo objetivo es } \\
\text { según Lukas (2003) ayudar } \\
\text { a mejorar su actitud frente } \\
\text { a algo. } \\
\text { La finalidad de estas pre- } \\
\text { guntas es la construcción } \\
\text { de experiencias satisfacto- } \\
\text { rias y llenas de sentido, ya } \\
\text { que cada persona dispone } \\
\text { de un poder de obstinación } \\
\text { del espíritu que le permite } \\
\text { trasformar un sufrimiento } \\
\text { inevitable en un acto huma- } \\
\text { no (Lukas, 2003). }\end{array}$ & $\begin{array}{l}\text { Se llevó a cabo por medio de un } \\
\text { cuestionario que consta de las } \\
\text { siguientes preguntas: } \\
\text { 1. ¿Qué significa para ti sentirse } \\
\text { bien? } \\
\text { 2. ¿En qué situación te sientes } \\
\text { bien después de la pérdida de } \\
\text { tu hijo? } \\
\text { 3. ¿Cuáles son tus puntos fuer- } \\
\text { tes y tus talentos? } \\
\text { 4. ¿Qué te haría sentir bien? } \\
\text { 5. ¿Qué te impide hacer lo que } \\
\text { te haría sentir bien? } \\
\text { 6. ¿Cómo puedes superar estos } \\
\text { obstáculos? } \\
\text { 7. ¿Que podrías hacer para } \\
\text { generar esa situación en la que } \\
\text { te sientes bien? } \\
\text { 8. ¿Existen otras situaciones } \\
\text { en las que te hayas sentido } \\
\text { igual a como te sentiste ante la } \\
\text { pérdida de tu hijo? } \\
\text { 9. ¿Cómo saliste de esa situa- } \\
\text { ción en la que te sentiste igual? } \\
\text { 10. ¿Has aprendido algo de } \\
\text { esas situaciones? }\end{array}$ \\
\hline $\begin{array}{l}\text { Sesión No.4 } \\
\text { Buscando la } \\
\text { resignificación } \\
\text { del } \\
\text { Sufrimiento }\end{array}$ & $\begin{array}{l}\text { Encontrar expe- } \\
\text { riencias positivas } \\
\text { dentro del suceso } \\
\text { para resignificar } \\
\text { el sufrimiento y } \\
\text { buscar un sentido } \\
\text { de vida. }\end{array}$ & $\begin{array}{l}\text { Modulación de la conduc- } \\
\text { ta: conseguir una actitud } \\
\text { interior positiva ante una } \\
\text { circunstancia negativa. } \\
\text { El método de modulación } \\
\text { de la conducta ayuda } \\
\text { activando la voluntad de } \\
\text { sentido por medio de la } \\
\text { elección libre de la actitud } \\
\text { frente al problema y de } \\
\text { dicha actitud volverá a } \\
\text { depender la manera de } \\
\text { soportar esa circunstancia } \\
\text { (Lukas, 2003). }\end{array}$ & $\begin{array}{l}\text { Por lo que dentro del discurso } \\
\text { de los padres se abordaron las } \\
\text { siguientes preguntas: } \\
\text { ¿Qué rescatas como positivo? } \\
\text { ¿Qué cosas aprecias ahora? } \\
\text { ¿En qué cosas has crecido o } \\
\text { madurado? }\end{array}$ \\
\hline
\end{tabular}




\begin{tabular}{|c|c|c|c|}
\hline $\begin{array}{l}\text { Número se } \\
\text { sesiones }\end{array}$ & $\begin{array}{l}\text { Objetivo } \\
\text { específico }\end{array}$ & Sustento teórico & Estrategia \\
\hline $\begin{array}{l}\text { Sesión No.5 } \\
\text { Reflexión de lo } \\
\text { adquirido. }\end{array}$ & $\begin{array}{l}\text { Que los padres } \\
\text { expresen el cómo } \\
\text { se sienten con la } \\
\text { intervención del } \\
\text { taller. }\end{array}$ & $\begin{array}{l}\text { Según Castanedo y Mun- } \\
\text { guía (2011) el proceso de } \\
\text { cierre compartido entre } \\
\text { facilitador y grupo permite } \\
\text { contrastar los resultados } \\
\text { con las expectativas desde } \\
\text { la subjetividad de los par- } \\
\text { ticipantes y se convierte al } \\
\text { mismo tiempo en evalua- } \\
\text { ción del taller y autoevalua- } \\
\text { ción del proceso personal. }\end{array}$ & $\begin{array}{l}\text { En la sesión número cinco } \\
\text { se llevó a cabo el cierre del } \\
\text { taller por lo que se realizó una } \\
\text { reflexión del cómo se sintieron } \\
\text { en el taller, que aprendizaje me } \\
\text { llevo del taller, como les ayudo } \\
\text { este taller. }\end{array}$ \\
\hline
\end{tabular}

Fuente: elaboración propia

Además, se analizó la etapa de duelo en la que se encuentran los padres y de esta manera tener una base de la cual partimos para llevar a cabo la intervención, ya que muchas personas necesitan la experiencia concreta de ver el cuerpo de un ser querido que ha fallecido porque eso hace que la pérdida sea real. Muchas familias de personas desaparecidas hasta la fecha no han encontrado la comprobación de la muerte, por lo que se encuentran en un desafío mayor para cambiar su percepción sobre la presencia o la usencia; de esta manera se intentó brindar ayuda por medio de un taller vivencial enfocado en la logoterapia en donde se realizaron diferentes actividades que permitieron la búsqueda de su sentido de vida.

\section{Resultados}

Después de la aplicación del taller se encontró que los padres pudieron darse cuenta que hay cosas positivas, a pesar del dolor y sufrimiento, estos resultados los plasmaremos en relación a las siguientes categorías:

1.-Circunstancias de las desapariciones: entendida como el momento y forma en que sucedió la desaparición. Lo que permite contextualizar la situación de los padres. 
La señora A nos menciona que su hijo fue extraído por la fuerza de su casa por lo que se presenta una desaparición forzada, pero al mismo tiempo es una desaparición común ya que no se solicitó un rescate y tampoco se presentan antecedentes judiciales o políticos.

La pareja B y C, es decir padre y madre, relatan que no hay testigos de la desaparición de su hijo, pero se puede encasillar en desaparición forzada ya que se solicitó un rescate.

Mientras que la señora $\mathrm{D}$ nos menciona que su hijo fue extraído por la fuerza de su negocio, por lo que entra dentro de la desaparición forzada.

En los casos en los cuales se solicitó rescate, los padres consiguieron la cantidad solicitada por los secuestradores, pero el rescate nunca concluyo puesto que la persona secuestrada nunca regresó a casa.

Los padres relatan que sus hijos no tenían nada que ver con bandas delictivas que llegaran a ser algún motivo para que se presentara su desaparición.

2. Estrategias para sobrellevar el duelo: el taller hizo traer al presente esos admirables recuerdos llenos de felicidad, permitiendo que se dieran cuenta que los recuerdos agradables prevalecen a pesar del sufrimiento.

Señora A: "dentro de la infancia de mi hijo recuerdo grandes momentos de felicidad, como es el caso del día de los reyes magos, otro momento se presentó cuando terminó la primaria, y así su vida estuvo llena de dicha, pero ninguna como el día de su boda y el nacimiento de su hija, mi nieta”.

Por otra parte, la señora B expresó que "los momentos que compartí con mi hijo, los logros académicos estos forman parte de los momentos felices" recordemos que la señora B es esposa del señor C. "Los dos estamos orgullosos de los logros de nuestro hijo, como el día que participo en la escolta del preescolar."

Mientras que la señora $\mathrm{D}$ dijo que "Mi hijo fue un niño que presento dificultades en el parto, pero al verlo crecer y jugar en el rio fue una gran alegría para mí como madre, pero el más bonito recuerdo de mi hijo fue el día que gano el primer lugar en ortografía."

Para Corless, Germino y Pittmann (2005) recordar los momentos agradables se considera parte del proceso de resolución del duelo, donde los padres 
pueden valorar la vida del hijo ausente y de esta forma seguir adelante sin que los sentimientos provocados por la pérdida los paralicen; es decir, indicar las oportunidades positivas de la vida existentes en cada momento y que no estén afectados por el sufrimiento, son oportunidades que el dolor actual no debe arrastrar. Se trata de salvar el resto. Sin querer sustituir lo perdido, a esto Lukas (2003) lo denomina mostrar el resto.

Por otra parte Frankl (1994), refiere que el sentido se esconde detrás de cada situación, por lo que evocar estos recuerdos ayudan a encontrar este sentido, ya que la conciencia es un órgano de sentido; dentro de esta categoría se evidenció cuáles son las estrategias que utilizan los padres, recursos se describen en la siguiente categoría.

3. Recursos personales: esta categoría está compuesta por el Autodescubrimiento: da cuenta de los recursos personales que los padres han utilizado para sobrellevar esta situación y la Responsabilidad: actitud de los padres ante su vida actualmente y ante sus otros familiares.

Auto-descubrimiento: en este aspecto se relata lo que cada uno de los padres compartió: la señora A “descubrí que no estoy sola, que debo de compartir porque eso me ha hecho bien, el dolor es muy grande y fuerte pero compartido pesa menos", y de esta manera la señora A también menciona lo siguiente, "apreció a mi familia, mi trabajo, mis hijos y sobretodo la vida.”

Mientras que la señora D, descubrió que “él ser egoísta me lleva a lastimar a mis seres queridos, de igual manera deseo pedir perdón a mi familia, a mis otros hijos, seguir adelante por mis hijos y mis nietos". La descripción que hacen los esposos que participaron en este taller, empezando por la señora B menciona lo siguiente: "yo entendí que tengo otros hijos que necesitan de mí," “crecí en un ambiente de paz con mis padres y hermanos y ahora nos encontramos en un ambiente lleno de terror por eso tengo que salir adelante para que mis hijos estén bien". El señor C nos menciona "He crecido como persona, dándole la mano a la gente, esta ayuda me hace más fuerte.”

Descubrir las propias cualidades es el primer paso para encontrar un sentido a la vida; en este aspecto los participantes del taller retoman el sentido que tenía su vida antes de la desaparición del hijo; es decir, el cuidado de la familia y los otros hijos para volver a sentirse en paz con ellos y con sus vidas. Como lo expresa Frankl (1991) "Lo que de verdad necesitamos es un cambio radical en nuestra actitud hacia la vida. Tenemos que aprender por nosotros mismos y después, 
enseñar a los desesperados que en realidad no importa que no esperemos nada de la vida, sino si la vida espera algo de nosotros” (p. 81).

En consonancia con lo anterior es importante retomar los valores existenciales que actúan como caminos que llevan a dar sentido a la vida; estos valores son de creación: la aportación al mundo de algo del propio ser y de su actuar. Vivencial: esta facilita la adquisición de los dones que la experiencia ofrece y regala. Y de actitud se refiere a la actitud humana ante el sufrimiento es decir, cómo lo soporta, como carga con él, pero los valores de actitud no modifican la realidad pero sí el cómo se observa esa realidad (Madrid, 2014).

Dentro de este campo, los padres describieron los siguientes: en el caso de la señora A "El amor a Dios me da la for taleza para cumplir con mis responsabilidades con mi madre, mi nieta, el amor a mi trabajo, familia, mis amigos, sobre todo a la vida y a mí misma, me hacen sentir bien y seguir con la búsqueda de mi hijo” la señora D dijo que "yo sé que fui egoísta que sólo pensé en mi dolor sin ver a mi alrededor, lo que sufrían mis hijas por la pérdida de su hermano y el hecho de verme sufrir, ahora entiendo que mi responsabilidad es pedir perdón por ser egoísta, expresar mi sentir y escuchar a mis hijas, buscando estar bien todos”.

La señora B "gracias a la ayuda de mis hijos y mi esposo hemos salido poco a poco adelante, pero sé que no estoy bien que me falta mucho, que es difícil” "entendí que mi responsabilidad o así lo creo yo es poner una actitud positiva, y de igual manera ver hacia el futuro, para poder estar bien, y esperar a que mi hijo regrese a su casa”.

El señor C “el saber que nuestros hijos están bien, sanos, el analizar las cosas y ver cómo podemos enfrentar la vida día a día, mi responsabilidad como padre y esposo creo yo es el dar un buen ejemplo para ellos, ya que hay muchas ocasiones en las que sufre uno por la ausencia de nuestro hijo, pero es bueno tropezar, caer y aprender a levantarse”.

Se manifiesta en estos relatos el valor vivencial, el cual se refiere principalmente al amor, como se observa en las narraciones el establecimiento de una entrega amorosa entre seres individuales en forma de amistad, paternidad y solidaridad (Madrid, 2014).

La logoterapia establece que es necesario aceptar las situaciones trágicas de la vida y no dejarse vencer por ellas; esto es parte de lo que se observó con los participantes del taller: las actitudes que asume frente al sufrimiento, a lo que es 
dado; ello puede hacer de más responsabilidad. La responsabilidad tiene 2 puntos de referencia intencional: el sentido (de cuyo cumplimiento somos responsables) y un ser delante del cual ser responsable (Fabry, 2005), el cual se ve reflejado en la revalorización que los participantes hicieron de su familia e hijo. Y de esta manera conociendo las estrategias empleadas y los recursos con que cuenta los padres damos paso a la visión de un nuevo sentido de vida en cual se describe en la última de las categorías.

4. Nuevo sentido de vida: compuesta por la Auto-trascendencia: la cual se entiende como la capacidad de descubrir una nueva orientación en la vida, hacia algo o mejor a alguien, que es esencial para resolver el duelo. Así como las Alternativas de elección: Tomar la decisión de vivir de manera positiva, disfrutando de lo que se tiene.

La auto-trascendencia: la observamos en los participantes de nuestro taller comenzando con lo descrito por la señora A, "el sentirme bien, el estar bien para mí y para mi nieta, que es el único recuerdo que me queda de mi hijo, es mi motivo para seguir adelante", mientras que la señora D "Dios me da fuerzas para seguir adelante y con esa fuerza poder ayudar a mi hija ya que ella paso por momentos similares a los que yo viví, la incertidumbre de ver que tu ser querido no llega a casa, pero gracias a Dios su esposo regresó sano y salvo con mi hija y mis nietos ellos me dan las ganas de seguir adelante ya que el estar con ellos me ayuda y me fortalece."

En de las descripciones la pareja B y C el señor C mencionó lo siguiente: "mis puntos fuertes es estar físicamente fuerte, mi trabajo para que mi familia este bien, pedirle a dios por mi hijo para que este bien en donde quiera que este y darle a nuestros demás hijos el cariño y la comprensión que necesitan”.

La Señora B dijo que “poco a poco me he sentido bien, mis hijos, mi esposo, me ayudan con sus abrazos y con sus palabras de aliento por lo que, pienso que yo tengo que estar bien para ellos y lograr salir adelante para estar bien con muestra familia”.

Las personas van resolviendo su duelo y encontrando los recursos que necesitan para salir adelante y continuar con su vida sin abandonar la esperanza de que sus hijos regresen o por lo menos saber qué fue de ellos. 
La auto-trascendencia se puede observar claramente pues Frankl (1994) la define como la facultad de llegar más allá de uno mismo, hacia amar a otros individuos y causas que pueda uno convertir en propias.

Dentro de esta categoría se contemplaron también las alternativas de elección de los padres, a partir de las preguntas: ¿En qué situaciones te encuentras bien después de la pérdida de tu hijo? Y ¿qué puedes hacer para generar situaciones en las que te sientas bien? Las respuestas de los participantes a la primera pregunta tienen que ver principalmente con asistir a la Iglesia y convivir con el resto de la familia.

La señora A: "Cuando voy a la iglesia y también cuando tengo a mi nieta conmigo y cuando pienso que el regresa.”

Señora B: "Cuando voy a la iglesia o cuando estoy con mis hijos y mi esposo."

Señor C: "Orar, pedir a Dios por mi hijo, estar con mis hijos, trabajando para lograr salir adelante.”

Señora D: "Estar en oración me calma, el cuidar a mis nietos, y cuando me van a comprar me siento contenta y tranquila.”

Para Frankl (1994) el sentido no sólo debe, sino que puede encontrarse y la conciencia guía al hombre en esta búsqueda; de esta manera, cuestionar sobre estos momentos en los que los padres se sienten bien trae una apertura a la búsqueda del sentido. De igual forma, Frankl (1994) nos habla de la posibilidad de distanciarse de una situación de los condicionamientos de sí mismo, esto es pues elegir libremente.

Mientras que en la segunda pregunta sus alternativas de acción se centran más en convivir con la familia, ser un buen ejemplo para los otros hijos, apoyar en su comunidad a quienes necesitan ayuda y ser realista para salir adelante. Así, la participante A expresó que "Asistir a la iglesia, pasar tiempo con mi nieta". Y la señora B: "Asistir a la iglesia, compartir con mis hijos, para que ellos me tenga confianza y me platiquen lo que les pasa y como se sienten.” El señor C relató que debe: "Escuchar a mis hijos, compartir con ellos todos los momentos que sean importantes para ellos y por otra parte, asistir al templo a orar.” Y finalmente la señora D: "Ser un poco más realista, seguir adelante y no ser egoísta." 
En estas familias la fe religiosa se presenta como una fortaleza y un consuelo para seguir adelante y afrontar la pérdida, tal como lo establece la logoterapia (Fabry, 2005), la espiritualidad y la religión son factores que ayudan a encontrar un sentido de trascendencia en la vida de las personas.

Lukas (2003), menciona que la libertad espiritual del hombre naturalmente no es una libertad de algo, estar libre de una influencia cualquiera sino una libertad para algo, ser libre para adoptar una postura frente a todas las influencias existentes para afirmarla o negarla, para seguirlas o resistirse a ellas; de este modo provocar en los participantes la elección y así adoptar una postura sobre salir a delante o que darse en el sufrimiento, ya que asegurar que el sufrimiento tiene un sentido equivale a decir que tiene un para qué, el cual se encuentra presente en la narrativa de los padres.

A partir de los discursos de los padres se confirmó la necesidad de un espacio seguro para hablar de sus hijos y de los sentimientos a los que se enfrentan día con día, también de cómo este espacio favoreció que surgieran actitudes positivas así como la resignificación de su vida después de este acontecimiento.

\section{Conclusiones}

Después de realizar el taller logoterapeútico se pudo apreciar que la desaparición de los hijos dificulta la resolución del duelo de los padres, ya que la no presencia de un cuerpo que lleve a la pérdida real, representa que sus hijos se encuentran con vida y que algún día regresarán. Para Allué (1998) el cadáver viene siendo el signo al que se le atribuyen significados que sustentan las creencias en torno a la muerte, de modo que la relación con el cuerpo permite restablecer el orden perdido con la ausencia. Sin embargo, la voluntad de sentido que es la fuente de motivación original del ser humano dice que el hombre está animado por una aspiración (Lukas, 2003).

Al respecto, Viktor Frankl (1991) menciona que si no está en tus manos cambiar una situación que te produce dolor, siempre se podrá escoger la actitud con la que se confronta: En ese sentido, el taller logró encaminar una actitud positiva con experiencias satisfactorias de crecimiento, por medio de la "conciencia que nos permite rastrear el único e irrepetible sentido que se esconde detrás de cada situación” Lukas (2003, p. 39). 
El taller logoterapeútico permitió encontrar nuevos sentidos y significados a la vida actual por medio del valor vivencial, el cual se refiere principalmente al amor, ya que pudieron recuperar el amor hacia su trabajo, a reunirse con familiares y amigos, a realizar aquellas cosas que disfrutaban y el anhelo a la vida, aún sin resolver el duelo, como establece Lukas (2003) los periodos de sufrimiento nos ofrecen la posibilidad de renacer y obtener un verdadero crecimiento personal.

También es importante mencionar el aspecto primordial que juega la religiosidad como valor para llegar a la autotrascendencia, ya que las madres de familia que participaron en el taller encuentran en su fe religiosa la fuerza para seguir adelante, tal como se menciona en la logoterapia que considera este aspecto como primordial.

Por lo tanto, se considera que promover la utilización de talleres logoterapéuticos con familiares de desaparecidos favorece la búsqueda de un nuevo sentido a la vida de los padres, la revaloración del resto de la familia y de los otros aspectos de su vida, lo que les permite salir adelante sin olvidar, pero sin centrar toda su vida en este duelo. Además, se genera un ambiente de empatía y comprensión, ya que todos pasan por la misma situación. Esto favoreció la creación de una red de apoyo entre los participantes que permanece aún después de terminado el taller. Y se extiende a aspectos prácticos y cotidianos de la vida, no solo al duelo.

A través de esta experiencia se pudo hacer alusión a la importancia que tiene como estrategia de intervención en la psicología clínica la implementación de talleres vivenciales. Con esto, futuras investigaciones pueden centrar su mirada en la utilización dichos talleres como una herramienta para trabajar con población que se puedan considerar vulnerables, ya que reportar los efectos de talleres vivenciales representa una estrategia para sistematizar un tipo de trabajo que es muy usual en la práctica de la psicología y que pocas veces se publica por la dificultad para presentar toda la información recabada en estos eventos.

Por eso, es necesario encontrar los modelos ideales para la presentación de la información importante y enfatizar las ventajas de las intervenciones grupales para atender determinadas problemáticas, como puede ser el manejo del duelo por desaparición. 


\section{Referencias}

Allué, M. (1998). La virtualización de la pérdida. Anuario de Psicología, 29(4), 67-82. Universidad de Barcelona.

Benenson, P. (2015). Información para el comité contra las desapariciones forzadas de la ONU. Recuperado de: http://amnistia.org.mx/nuevo/wpcontent/uploads/2015/02/amr410012015es.pdf

Bravo, E., Duran, F. y Trujano, M. (2014). Duelo de los familiares por personas desaparecidas en México. (Tesis de Maestría, inédita). Asociación Mexicana de Tanatología México D.F.

Castanedo, C. y Munguía (2011). Diagnóstico, intervención e investigación en psicología humanista. Madrid: CCS.

Censo de Población y Vivienda (2010). Panorama sociodemográfico de Guerrero / Instituto Nacional de Estadística y Geografía.-- México: INEGI, (2011).Recuperado de http://www.inegi.org.mx/prod_serv/contenidos/ espanol/bvinegi/productos/censos/poblacion/2010/panora_socio/gro/ Panorama_Gro.pdf

Corless, I., Germino, B. y Pittman (2005). Agonía, muerte y duelo. Un reto para la vida. México: Manual moderno.

Fabry, J. (2005). La búsqueda de significado. México: LAG.

Fabry, J. (2001). Señales del camino hacia el sentido. México: LAG

Frankl, V., (1991) .El hombre en busca de sentido. Barcelona: Herder.

Frankl, V. (1994). La voluntad de sentido. Barcelona: Herder.

Gómez, J. D., Giraldo, L. A., Maestre, K. (2008). Niveles de depresión y estrategias de afrontamiento en familiares de víctimas de desaparición forzada en la ciudad de Medellín. International Journal of Psychological Research, 27-33.

Lukas, E. (2003). Logoterapia: La búsqueda de sentido. México: Paidós. 
Lukas, E. (2008).También tu vida tiene sentido. México: LAG.

Luna, J. (2002). Soledad y depresión, Los círculos del dialogo una estrategia desde la logoterapia. Colombia: San Pablo.

Madrid, J. (2014), Manual de relación de ayuda integrativa. España: Punto rojo libros.

Rodríguez, G., Gil, J. y García, E. (1999). Metodología de la investigación cualitativa. México: Aljibe.

Sierra, M. (2015). Emergentes respuestas locales a la violencia y a la Impunidad: Ayotzinapa y la crisis de la seguridad pública en Guerrero, México. ( $L A S$ AFORUM) Centro de investigación y estudios superiores en Antropología Social, CIESAS, 46(2), 19-24.

Soria, H. (2014).Testimoniales de violencia. Acercamiento psicoanalítico a su discurso y a su drama subjetivo. México: Kanankil

Procuraduría General de la República (2015). Información estadística sobre la desaparición de personas. Recuperado de www.pgr.gob.mx/Transparencia/Paginas/desaparicion-personas 